\title{
Simulation of Extrusion and Die Design of Plastic Gear
}

\author{
Zhihong $\mathrm{Fu}^{1, \mathrm{a}}$, Chen $\mathrm{YaO}^{1, \mathrm{~b}}$, Jinxia Zhang ${ }^{1, \mathrm{c}}$, Wei Liu ${ }^{1, \mathrm{~d}}$ \\ ${ }^{1}$ College of Mechanical and Electrical Engineering, Central South University, Changsha, 410083, \\ China \\ azhihongfu@ csu.edu.cn, ${ }^{b} 540924947 @ q q . c o m,{ }^{c} 1099948680 @ q q . c o m,{ }^{d} 1025251318 @ q q . c o m$
}

Keywords: Plastic gear, Extrusion, Inverse extrusion, Simulation, Die.

Abstract. The FEM simulation of flow of extruding plastic gear during cooling and die design was studied in this paper. A capillary rheometer MLW-400 was used to measure the curve of shear rate VS viscosity of POM-500P, the Power Law constitutive equation was used to describe the POM rheological characteristics, the software POLYFLOW was used to simulate the structure parameters of flow channel for 16 sets of orthogonal tests, so the best structure parameters of flow channel which has good flow uniformity were obtained. The die of plastic gear was designed using the function of inverse extrusion of POLYFLOW. The cooling process of plastic gears in the vacuum shaping mold was simulated with software ANSYS, and the length of mold was determined as 160 $\mathrm{mm}$.

\section{Introduction}

With the improvement of the polymer material performance, plastic products have the advantages of light quality, low cost, high precision, oxidation resistance, corrosion resistance, self-lubrication, easy molding, high specific strength, etc., plastic products such as plastic gear have become a first choice in the field of electronic communications, instrumentation, aerospace and automotive, communications, medical, and other areas in modern industrial[1]. Generally, injection moulding is a widely used method[2]. However, for spur gears, extrusion is the best method due to the fixed section. Because extruded gear has strict requirement of dimension accuracy which is different from general pipe and rod extrusion, Polyflow software is carried for the numerical simulation to obtained the optimized structure parameters of the flow channel of die, thermal analysis module of ANSYS is used to simulate the cooling process of plastic gears to determine the length of vacuum shaping mold.

\section{Choosing the constitutive equation}

The constitutive equation should be determined before using POLYFLOW to simulate the extrusion of plastic gear. POM is a homopolymer and crystalline plastics, and is one of the most widely used material which has high quality to resist creeping and stress relaxation, and its wear resistance, self-lubrication and fatigue resistance are superior to a vast majority of engineering plastics.

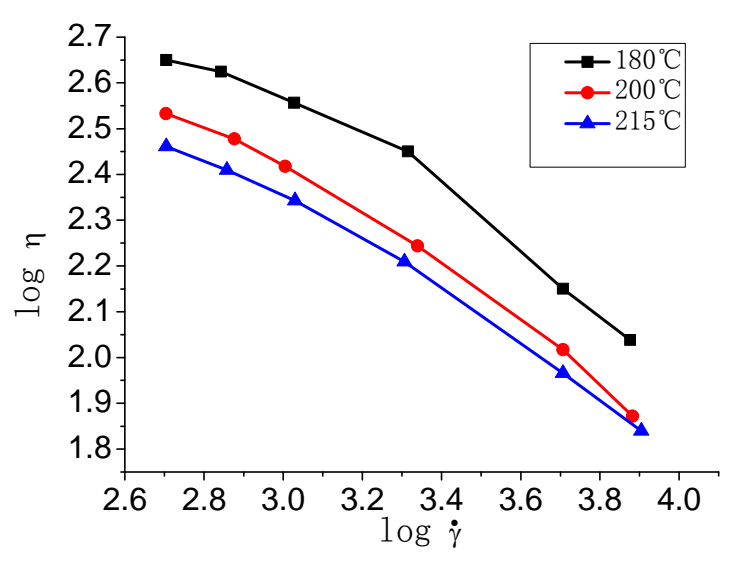

Figure 1. $P O M-500 P$ double logarithmic curve of shear rate VS viscosity.
Melting point is clear, once reached melting point, the melt viscosity drops rapidly. So, POM-500P, produced by DuPont, is used as the materials of gear in this paper. POM-500P melt has obviously the characteristics of shear thinning behaviors, which belongs to the non-Newtonian pseudoplastic fluid [3], so the rheological behavior of POM-500P matches the Power Law constitutive equation model, for viscosity is:

$$
\eta=\eta_{0}(\lambda \cdot \dot{\gamma})^{(n-1)}
$$

Where $\eta_{0}$ is the consistency factor, $\lambda$ is the relaxation time, $\dot{\gamma}$ is the shear rate, and $n$ is 
the power-law index. All these parameters will be decided by experiment.

\subsection{Rheological test and data processing}

Experimental apparatus was a capillary rheometer MLW-400. Experiment temperature is set as $180{ }^{\circ} \mathrm{C}, 200{ }^{\circ} \mathrm{C}$ and $215^{\circ} \mathrm{C}$, the length-diameter ratio of extrusion die is $10 \mathrm{~mm}$, the loading speed is constant. Viscosity data of POM-500P at different temperature was shown in Fig 1.which is a double logarithmic curve of shear rate VS viscosity .

\subsection{Determining parameters of the constitutive equation}

The parameters in equation (1) is shown in table 1 which is fit with Polymath software from figure 1 .

Table1. Power Law constitutive equation parameters under different temperature.

\begin{tabular}{cccc}
\hline Temperature & $\eta_{0}$ & $\lambda$ & $\mathrm{n}$ \\
\hline $180^{\circ} \mathrm{C}$ & 238.0988 & $0.4890926 \mathrm{e}-03$ & 0.4635954 \\
$200^{\circ} \mathrm{C}$ & 169.3964 & $0.4921852 \mathrm{e}-03$ & 0.4371786 \\
$215^{\circ} \mathrm{C}$ & 148.2188 & $0.4830827 \mathrm{e}-03$ & 0.4748996 \\
\hline
\end{tabular}

\section{Die design of plastic gear}

\subsection{Range of parameters of flow channel}

The parameters of POM gear are modulus $m=0.5$, teeth number $z=12$, central hole diameter $2 \mathrm{~mm}$, addendum circle diameter $6.8 \mathrm{~mm}$ as shown in figure 2 , the parameters of flow channel in the die are the length of shaping section $L_{1}$, the length of compression section $L_{2}$, the length of split Cone $L_{3}$, the length of split segment $L_{4}$, the total length of channel, the diameter of inlet $D_{0}$, the split angle $\alpha$, the compression angle $\beta$ as shown in figure 2. The parameters of flow channel values range is shown in table 2.

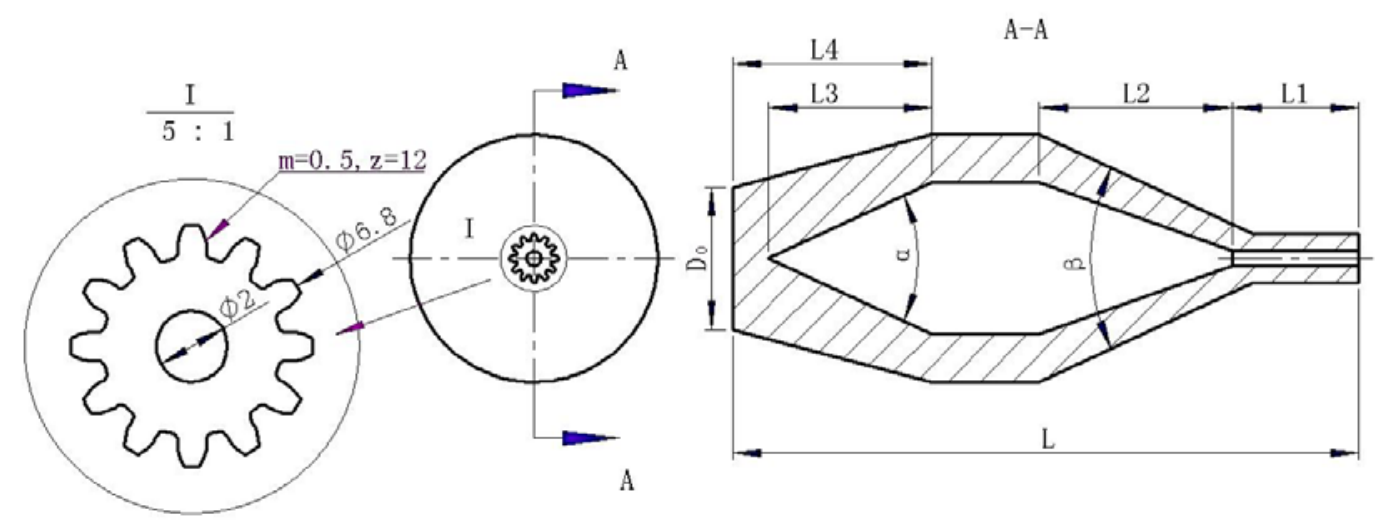

Figure2. Gear extrusion flow channel structure.

Table2. Range of plastic gear flow channel parameters.

\begin{tabular}{cccc}
\hline Setting section length L1/mm & $3.4 \sim 20.4$ & Port entrance diameter $\mathrm{D}_{0} / \mathrm{mm}$ & 20 \\
\hline Compressed length L2/mm & $30 \sim 50$ & Shunt angle $\alpha /{ }^{\circ}$ & $30^{\circ} \sim 60^{\circ}$ \\
Shunt cone length L3/mm & $20 \sim 30$ & Compression angle $\beta /{ }^{\circ}$ & $30^{\circ} \sim 50^{\circ}$ \\
\hline
\end{tabular}

\subsection{Uniformity analysis of different parameter combination}

A gear die which has good flow uniformity is necessary for extrusion of plastic gear is more complex than that of general extrusion. Every structure parameters of die influences the flow uniformity. The orthogonal test of five factors (A, B, C, D, E) ,four levels $(1,2,3,4)$ are used to analysis the flow uniformity according to the parameter value range specified in the table 2 . These 16 groups of flow uniformity of channel structure are compared in a quantitative way, 24 test points were selected in the area of exit section of the die ((taken 1/24 of the gear, namely half a tooth of 
the $3 \mathrm{D}$ model tooth as the simulation object to improve the computing speed and efficiency, for the reason of symmetry). The extrusion speed of test point is used to judge the flow uniformity[4]. The position of test point was shown in figure 3 .

Test point was divided into zones $\mathrm{A}$ and $\mathrm{B}$, zone $\mathrm{A}$ including points $1 \sim 22$, zone $\mathrm{B}$ including points $23 \sim 44$, the flow uniformity difference indicator of zone $\mathrm{A}$ and $\mathrm{B}$ is $\mathrm{FH}$

$$
F H=\left|\frac{\overline{V_{B}}-\overline{V_{A}}}{\overline{V_{A B}}}\right|
$$

Where, $\overline{\mathrm{V}_{\mathrm{A}}}=\frac{1}{22} \sum_{1}^{22} \mathrm{v}_{\mathrm{i}}, \overline{\mathrm{V}_{\mathrm{B}}}=\frac{1}{22} \sum_{1}^{22} \mathrm{v}_{\mathrm{i}}$ represent the average speed of $\mathrm{A}$ and $\mathrm{B}$ zone respectively, $v_{i}$ represent the speed of point NO.(i), $\overline{V_{A B}}=\left(\overline{V_{A}}+\overline{V_{B}}\right) / 2$ represent the average speed of the whole area.

According to typical produce conditions of $P O M$ rod, the head temperature of $200^{\circ} \mathrm{C}$ for 16 group of structure parameters was chosen for numerical simulation[5]. According to the results of the numerical simulation of Polyflow, 16 groups of 44 points speed value of the flow channel were exported in CFD-Post, and the date was batch processed in Excel, the flow uniformity difference indicator FH was calculated, and the result is shown in table4.

Table 3. Flow uniformity difference index of orthogonal test.

\begin{tabular}{cccccccc}
\hline 1 & 2 & 3 & 4 & 5 & 6 & 7 & 8 \\
\hline 0.787515 & 0.789883 & 0.791343 & 0.821156 & 0.749124 & 0.83114 & 0.834712 & 0.830554 \\
9 & 10 & 11 & 12 & 13 & 14 & 15 & 16 \\
0.847465 & 0.832452 & 0.821494 & 0.837147 & 0.808687 & 0.822364 & 0.852484 & 0.85248 \\
\hline
\end{tabular}

According to the data in table 4, the minimum difference of the uniformity is the 5th group, the velocity distribution contour of exit section are shown in figure 4,its specific conditions is A2, B1, $\mathrm{C} 2, \mathrm{D} 3, \mathrm{E} 4$, and its flow channel structure parameters is shown in figure 5.

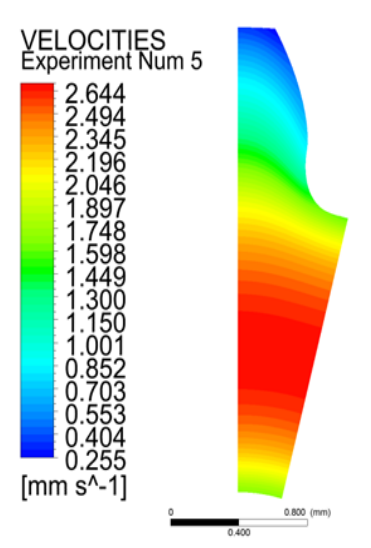

Figure3. Test point position.

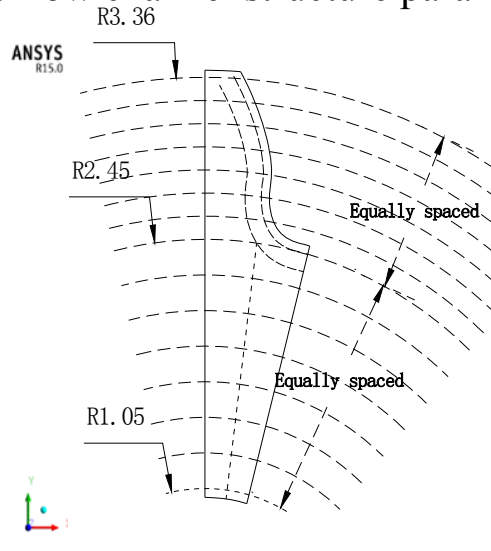

Figure4.Velocity distribution contour of 5 th group

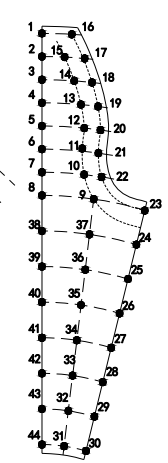

Figure5. Flow channel structure of 5 th group.

\subsection{Reverse design of plastic gear extrusion die}

According to the result of 3.2, the plastic gear die was reverse designed by die setting section length using Polyflow inverse extrusion function. It is concluded that extrusion die mold for plastic gears cross-section shape as shown in figure 6.

\subsection{Design of $v$ vacuum shaping mold}

Compared with plastic tubing or rod, plastic gear has higher requirements of the dimensional accuracy and surface roughness. However, the surface quality mainly depends on vacuum shaping mold and which also has affections in dense degree of extrusion products. Extrusion of plastic gear with the method of vacuum negative pressure setting and recycled water cooling, make use of the transient thermal analysis module of ANSYS to determine the length of cooling setting section. The analysis time was set in $100 \mathrm{~s}$, time step was $1 \mathrm{~s}$, the minimum time step was $1 \mathrm{~s}$, and the maximum 


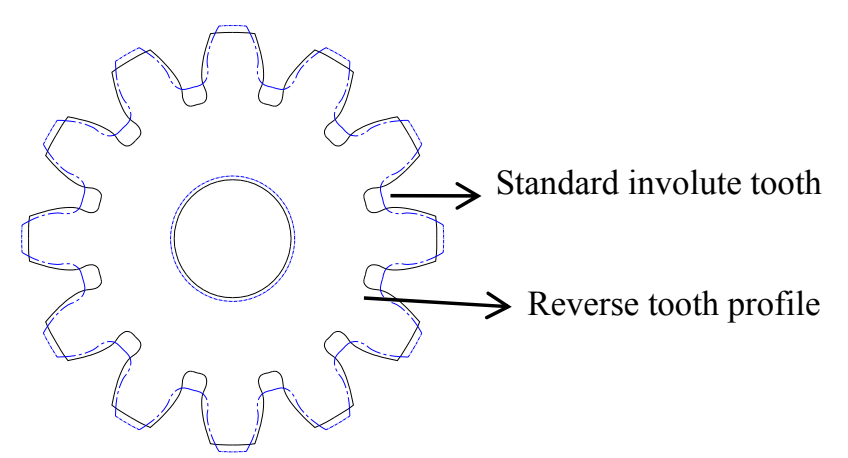

Fig .6. Cross-section of extrusion die mold

time step was $2 \mathrm{~s}$. The calculation results of 25 th (calculate time $=47.866 \mathrm{~s}$ ) analysis step in the process of cooling is shown in figure 7, the results could be draw out that the addendum circle cooling fastest in $33.832{ }^{\circ} \mathrm{C}$, the highest temperature was in the center of hole, in which the temperature was $46.9429{ }^{\circ} \mathrm{C}$. Taking four temperature measurement point in the radial direction, and pointed 1, 2, 3, 4, the changing trend of temperature was shown in figure 8.In 80 seconds, the temperature of the whole model was close to room temperature $25{ }^{\circ} \mathrm{C}$. According to the value of extrusion speed which was $2 \mathrm{~mm} / \mathrm{s}$, the determined cooling setting section length is $160 \mathrm{~mm}$.

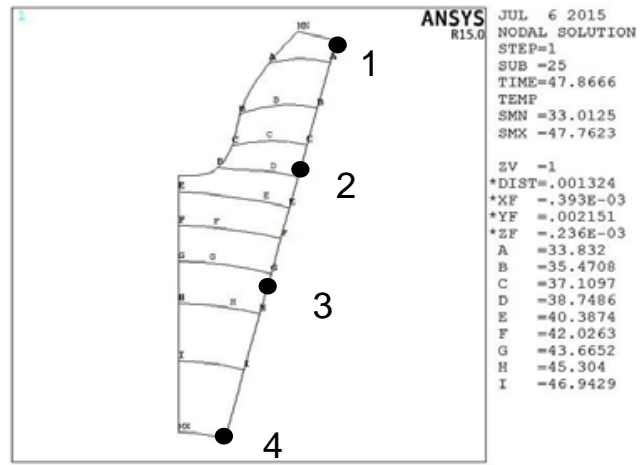

Figure.7. Results of 25 th analysis step.

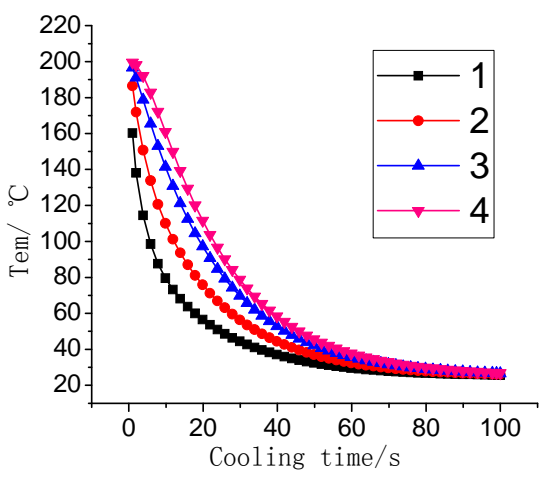

Figure.8. Cooling curve in vacuum shaping mold

\section{Conclusion}

Apart from the injection molding, a new gear forming method-extrusion is proposed. Traditional experience is combination with numerical simulation in this paper. The channel, die section and vacuum shaping mold of plastic gear extrusion die are simulated using the way of combination of traditional experienced method and numerical simulation, the gear die and vacuum shaping mold are designed, the design efficiency of extrusion die is greatly improved.

\section{Acknowledgements}

This work was financially supported by the Hunan Province Key R \& D program (application of basic research)( 2015JC3008).

\section{References}

[1] K.Masaya, U.Yoshitaka, I.Tomoaki and N. Susumu: Wear, Vol.254(2003), p.468.

[2] Y.W.Li: Chin. Plast. Ind.. Vol.39(2011), p.4.

[3] C.S.Chen, S.C.Chen, W.L.Liaw, R.D. Chien: $\quad$ Eur. Polym. J., Vol.44(2008), p.1891-1892.

[4] D.Y.Zhao, Y.F.Jin, M.J.Wang, K.Li, M.C.Song: 2009 IEEE International Conference on Mechatronics and Automation, IEEE Computer Society,p.3155-3160.

[5] Mechatronics and Automation, 2009. ICMA 2009. International Conference on. IEEE, 2009.

[6] D.D.Zhong, H.Wang: Plastic, Vol.17(1988),p.36-39. 